\title{
Parry-Romberg Syndrome: An Orthodontic Perspective
}

\author{
${ }^{1}$ Garima A Arya, ${ }^{2}$ Sunita S Shrivastav, ${ }^{3}$ Krishna G Sharma, ${ }^{4}$ Ranjit H Kamble
}

\begin{abstract}
Parry-Romberg syndrome is a rare disorder of unknown etiology, which causes asymmetry of the face. The syndrome presents with characteristic skeletal, dental, and soft tissue changes in the affected half of the face, with or without neurological signs and symptoms. The nature of the disease results in psychological disturbances and also dental anomalies. This article reports a case of a 23-year-old male who presented with classical features of the syndrome.
\end{abstract}

Keywords: Hemifacial atrophy, Parry-Romberg syndrome, Progressive facial hemiatrophy.

How to cite this article: Arya GA, Shrivastav SS, Sharma KG, Kamble RH. Parry-Romberg Syndrome: An Orthodontic Perspective. Int J Recent Surg Med Sci 2017;3(1):48-52.

Source of support: Nil

Conflict of interest: None

\section{INTRODUCTION}

Parry-Romberg syndrome (PRS) was first described by Caleb Hillier Parry in 1825 and Moritiz Heinrich Romberg in 1846. The term progressive facial hemiatrophy (PFH) was coined by Eulenberg in $1871 .^{1}$ It is characterized by a progressive, but self-limited atrophy of the skin and subcutaneous tissue on one side of the face. ${ }^{2,3}$ There is a progressive wasting of subcutaneous fat, sometimes accompanied by the atrophy of skin, cartilage, bone, and muscle. ${ }^{4}$

The onset of this syndrome occurs in the first and second decades of life. The atrophy progresses slowly during the years and then it stabilizes on its own..$^{5-7}$ Patients who manifest atrophy in early ages have bigger impacts, and it is directly related to the growing age of the patient. ${ }^{8}$ This syndrome has a higher incidence in women. ${ }^{9-11}$ The extension of the atrophy is frequently limited to one side of the face; only 5 to $10 \%$ of cases were described as being bilateral. ${ }^{12}$

\footnotetext{
${ }^{1}$ Postgraduate Student, ${ }^{2}$ Professor and Head, ${ }^{3}$ Senior Lecturer ${ }^{4}$ Professor

${ }^{1-4}$ Department of Orthodontics and Dentofacial Orthopaedics Sharad Pawar Dental College \& Hospital, Wardha, Maharashtra India

Corresponding Author: Garima A Arya, Postgraduate Student Department of Orthodontics and Dentofacial Orthopaedics Sharad Pawar Dental College \& Hospital, Wardha, Maharashtra India, Phone: +919096448950, e-mail: drgarimaaarya@ gmail.com
}

The exact etiology and pathogenesis of PFH is not well understood. It seems to be heterogeneous. Cerebral disturbance of fat metabolism, endocrine disturbances, local facial trauma autoimmunity, heredity, hyperactivity or hypoactivity of the sympathetic nervous system, abnormality of the trigeminal nerve and viral infections, including Borrelia burgdorferi are believed to be associated with the pathogenesis of this disease. ${ }^{13-15}$ Some inherent relationship between PRS and the disorder of neural crest cell migration has also been proposed as etiology of this condition. ${ }^{16}$

\section{CASE REPORT}

A 23-year-old male was referred to the Department of Orthodontics and Dentofacial Orthopaedics, Sharad Pawar Dental College \& Hospital, Wardha, India, with chief complaint of deformity of face and crocked teeth in front region of jaw. On detailed history taking, it was observed that patient had progressive atrophy on right side of face, which was initiated at the age of 7 years until 19 years. On physical examination, it was noted that this patient had marked facial asymmetry with marked hypoplasia of right side of face, and the deviation of lip toward right side of face caused lip incompetency (Fig. 1A). Alopecia was noted at postauricular area, and there was no beard on affected side (Figs 1B and C). Patches of hyperpigmentation were seen on affected side (Fig. 1D). On temporomandibular joint (TMJ) palpation, there were clicking present on right side.

Intraorally, there was mild crowding seen with upper and lower anterior teeth. There was cross-bite present on right buccal segment from canine to second premolar. Occlusal canting was seen due to atrophy on right side. Maxillary and mandibular arch asymmetry was seen with marked constriction in right maxillary segment. There was missing lower first molar bilaterally. Patient gave history of extraction with lower right and left first molars due to caries at a private dental hospital. Prosthesis was seen with lower right and left second premolar, first molar, and second molar. Atrophy was present on right side of tongue, which leads to deviation of tongue tip toward right (Figs 2A to F).

Radiographically, there was asymmetry present along with decreased vertical height of ramus and maxillary alveolar process on right side. In orthopantomogram (OPG), there was bone loss seen below the bridge for left first molar (Figs 3A and B). Cephalometric measurements of patient showing skeletal class I relation of jaws (SNA83o, SNB-80o, ANB-3o) (Fig. 4). 


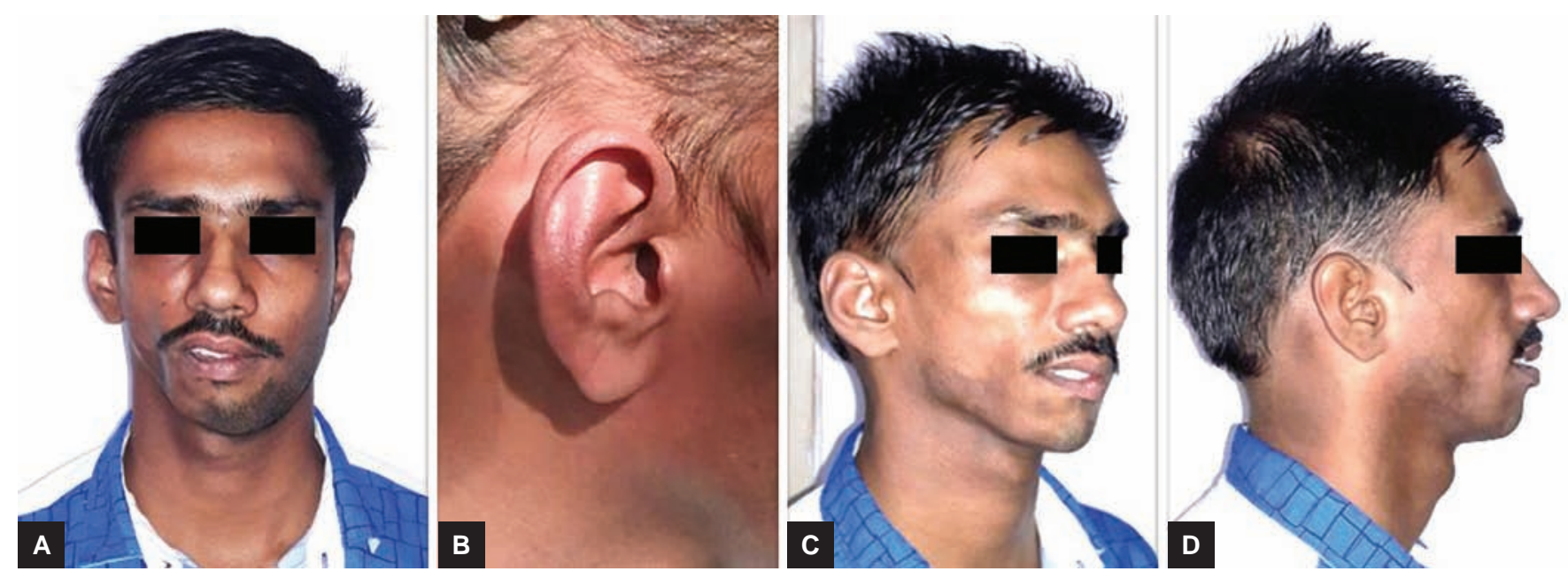

Figs 1A to D: Extraoral view of patient. (A) Atrophy of right side of face, deviation of lip toward right side; (B and C) No hairs on affected side; and (D) Hyperpigmentation on affected side
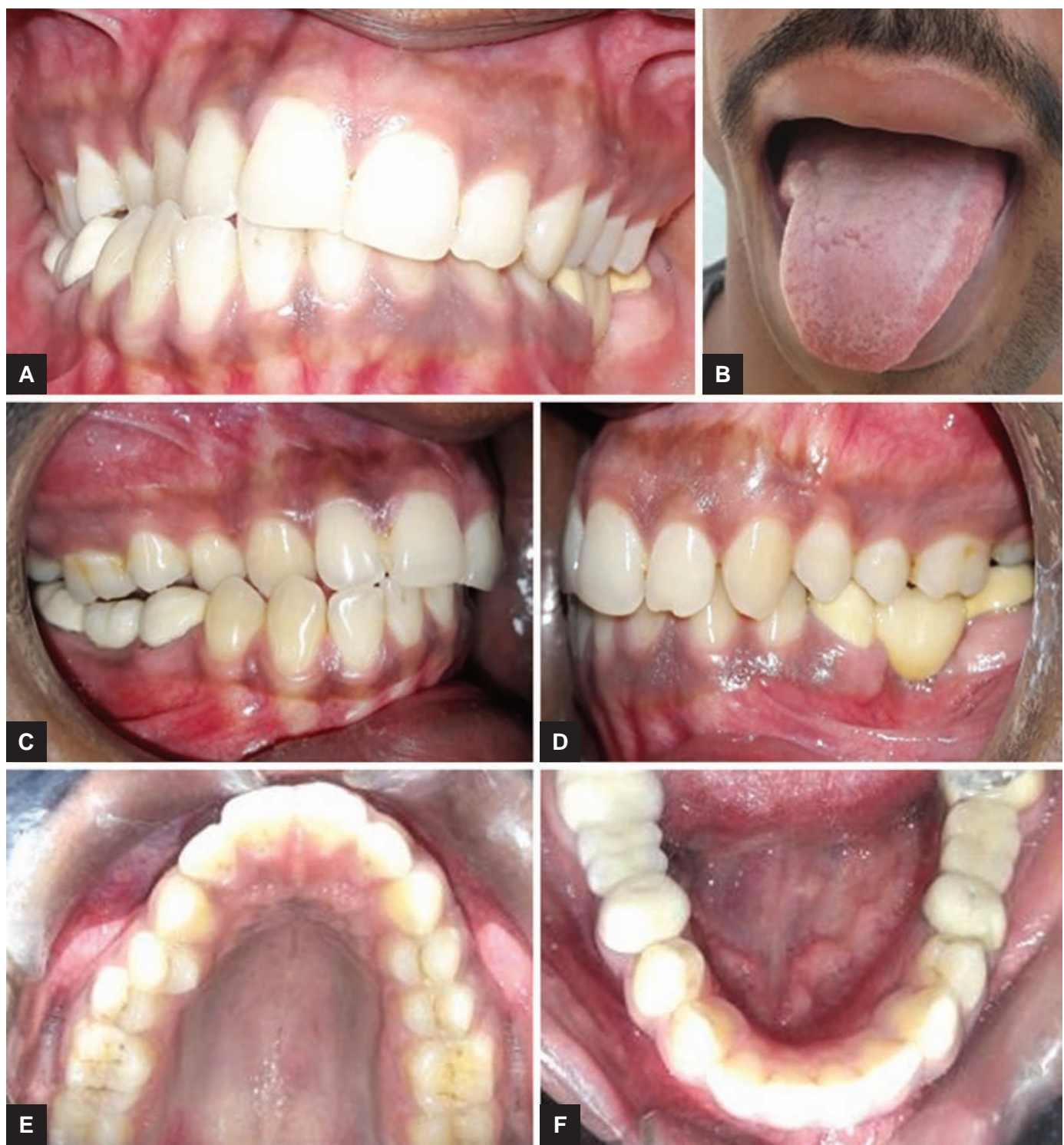

Figs 2A to F: Intraoral view of patient showing crowding, cross-bite in right side and atrophy of tongue on same side, constricted maxillary segment on right side 


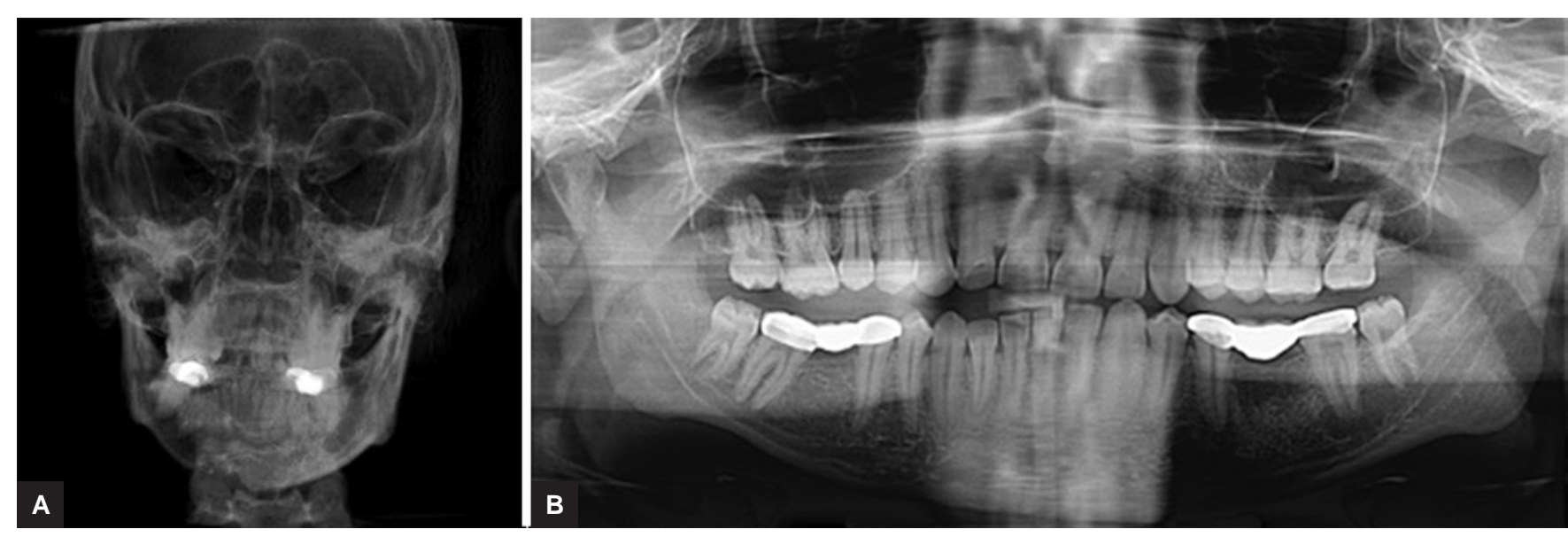

Figs 3A and B: Posteroanterior skull and OPG of patient showing marked skeletal atrophy on right side

Histopathological report of skin biopsy showed atrophied dermis and epidermis suggestive of scleroderma.

Patient presented with good general health without obvious illness that would explain the cause of PFH.

Based on clinical, radiological, and histological examinations, the diagnosis of PRS with skeletal class I, dentoalveolar Angle's class I Dewey's type III malocclusion was made.

\section{Problems List}

- Facial asymmetry

- Temporomandibular joint clicking

- Cross-bite from right canine to second premolar

- Mild anterior crowding

- Constricted arches

- Thin buccal soft tissue on affected side and lip deviation toward right side.

\section{Treatment Planning}

As patient's growth was completed and progression of disease also stopped, corrective treatment procedure was planned, which included the following:

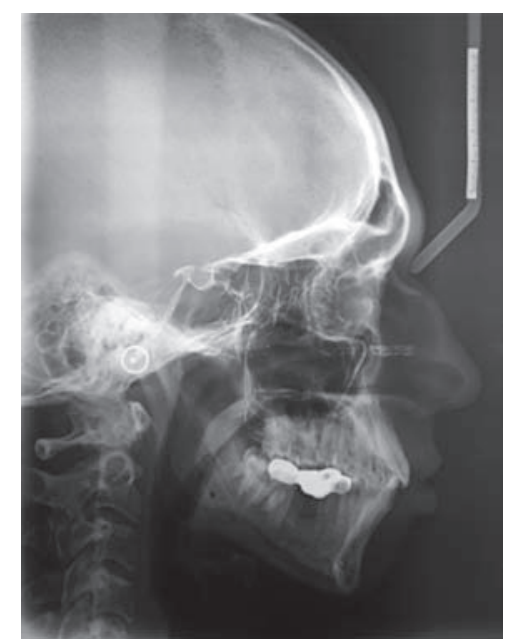

Fig. 4: Lateral cephalogram of patient
- Face bow relation to evaluate and coordinate centric relation and centric occlusion

- Fixed orthodontic mechanotherapy with MBT 0.022" slot to align the teeth on their jaw bases and for correction of cross-bite followed by finishing and detailing of occlusion

- Esthetic reconstruction on right side of face

\section{DISCUSSION}

The PRS is an uncommon condition comprising unilateral atrophy of the face. The onset of the disease is in the first two decades, with a progressive phase lasting 2 to 20 years, and then a stable phase sets in.

Etiology is not clear for this condition. Various causes, such as cerebral lesion, viral infections, endocrine disturbances, trauma, autoimmunity, and hereditary have also been suggested. Cory et $\mathrm{al}^{17}$ postulated that there is a diffuse self-limiting inflammatory process associated with the cervical sympathetic ganglia and carotid plexus, resulting in hyperactivity of the sympathetic system. They described a case of a 5-year-old with initial migraine-type headaches accompanied by sensorimotor symptoms, followed by development of typical facial changes. Blitstein and Vecchione ${ }^{18}$ suggested that the primary event is a neurovasculopathy and associated it with the systemic vasculitis of scleroderma. Tang et $\mathrm{al}^{16}$ believed that some inherent relationship between PRS and the disorder of neural crest cell migration may exist, and that malformation or disturbed migration of neural crest cells might be relevant. In the present case, the cause of atrophy remained unclear.

Unilateral atrophy of the skin, subcutaneous fat, and rarely muscle and bone are present with this syndrome, resulting in facial asymmetry. Earliest change is observed as a cleft near the facial midline. Skin is tensed or fibrosed with loss or gain of pigmentation associated with hair defects, which manifests as focal baldness and facial hair 
loss. The changes involve the dermatome at one or more branches of the trigeminal nerve. Enophthalmos may be present due to loss of periorbital fat, and rarely uveitis and retinal vasculitis. ${ }^{19}$ Ear on the affected side may be smaller, although no functional defects in the eye and ear are observed. ${ }^{5}$

The oral mucosa and tongue can be affected, as also are jaws, salivary glands, and teeth. Deviation of the mouth and nose toward the affected side may be seen. Reduction in tongue size along with jaw hypoplasia may be manifested because of syndrome. ${ }^{13}$ Lip atrophy usually leads to unilateral exposure of teeth. Muscle wasting has been described in certain cases. ${ }^{5}$

Neurological symptoms include trigeminal neuralgia, migraine type headache, facial paresthesia, and focal epilepsy. Radiological studies show ipsilateral cerebral changes. The computed tomography of the brain reveals focal cerebral hypodensities and intracranial calcifications, and magnetic resonance imaging shows focal white matter enhancement, cortical thickening, and meningeal enhancement. Vascular anomalies like intracranial aneurysms, reversible vasoconstriction, and vascular malformations have also been reported. ${ }^{17,20,21}$ In the present case, there were no neurological signs and symptoms present.

Histopathological examination of skin reveals that dermis and epidermis of skin and subcutaneous tissue are atrophied along with atrophy of hair follicles. There is atrophy of subcutaneous fat and degenerative changes are seen in vascular endothelium. ${ }^{11}$ Perivascular chronic inflammation is variable, and distinguishes from localized scleroderma where the perivascular inflammation is massive, especially in the early stages. ${ }^{20}$

Diagnosis of PRS is based on detailed patient history and clinical examination, which is also supported by imaging and histopathological studies. The severity of the condition depends on the age of onset and may or may not correlate with the extent of cerebral pathology. ${ }^{18,22}$

Multidisciplinary attendance of physicians, dentists, otolaryngologists, orthodontists, surgeons, and psychologist are needed to treat this condition. The treatment is usually based on esthetic reconstruction, which involves reposition of adipose tissue that was lost due to atrophy. Autogenous fat graft, cartilage graft, silicon injections, and prosthesis, bovine collagen, and inorganic implants are alternatives to treat this condition. Treatment of neurological disorder is also necessary. ${ }^{7}$ Esthetic correction can be performed after stoppage of disease progression. In the present case, disease progression was stopped four year back according to patient history; hence, esthetic reconstruction can be performed preferably by autogenous fat graft.

Jun et $\mathrm{al}^{23}$ described two cases of the syndrome where they found lack of success in surgical correction, which was performed in the third and fourth decades of life. Grafting, flap surgery, bone distraction, and steroid injections were attempted by them for the esthetic management of the patients. Lazaridou et $\mathrm{al}^{24}$ pointed out the lack of sufficient literature regarding efficacy and safety of steroids and other drugs used to treat the syndrome. Grippaudo et $\mathrm{al}^{25}$ describe the orthodontic therapy for PRS. Orthodontic therapy during puberty allows patients affected by PFH to present a more harmonic face at the end of puberty when final reconstruction can be planned. These results provide for a limitation of surgical intervention to the sclerodermic area alone.

\section{CONCLUSION}

The PRS is an uncommon condition, which manifests as atrophy of one side of the face. In most cases, PRS appears to occur for unknown reasons. The pathophysiology of the syndrome remains unknown. We, hereby, present a case of PRS with classical features. If diagnosed much earlier in life, the developing facial deformity could have been prevented. More research is necessary to assess safety and efficacy of management of this incurable disease.

\section{REFERENCES}

1. Regezi, JA.; Scuibba, JJ.; Jordan, RCK. Oral pathology: clinical pathological correlations. 4th ed. St. Louis (MO): Saunders/ Elsevier Science; 2003.

2. Padmini P, Singhi PD. Facial hemiatrophy. Indian Pediatr 1992 Apr;29(4):505-507.

3. Gulati S, Jain V, Garg G. Parry-Romberg syndrome. Indian J Pediatr 2006 May;73(5):448-449.

4. Rogers BO. Progressive facial hemiatrophy: Romberg's disease: a review of 772 cases. Proceedings of 3rd International Congress Plastic Surgery. Excerpta Medica ICS 1964;66: 681-689.

5. Mazzeo N, Fisher JG, Mayer MH, Mathieu GP. Progressive hemifacial atrophy (Parry-Romberg syndrome). Oral Surg Oral Med Oral Pathol Oral Radiol Endod 1995;79:30-35.

6. Moore MH, Wong KS, Proudman TW, David DJ. Progressive hemifacial atrophy (Romberg's disease): skeletal involvement and treatment. Br J Plast Surg 1993 Dec;46(1):39-44.

7. Roddi R, Riggio E, Gilbert PM, Hovius SE, Vaandrager JM, van der Meulen JC. Clinical evaluation of techniques used in the surgical treatment of progressive hemifacial atrophy. J Craniomaxillofac Surg 1994 Feb;22(1):23-32.

8. Neville, BW.; Damm, DD.; Allen, M.; Bouquot, JE. Patologia oral e maxillofacial. 4th ed. Rio de Janeiro: Elsevier; 2016. p. 35.

9. Finesilver B, Rosow HM. Total hemiatrophy. JAMA 1938 Jan 29;110(5):366-368.

10. Jurkiewicz MJ, Nahai F. The use of free revascularized grafts in the amelioration of hemifacial atrophy. Plast Reconstr Surg 1985 Jul 1;76(1):44-54.

11. Pensler JM, Murphy GF, Mulliken JB. Clinical and ultrastructural studies of Romberg's hemifacial atrophy. Plast Reconstr Surg 1990 May 1;85(5):669-674. 
12. Miller MT, Sloane H, Goldberg MF, Grisolano J, Frenkel M, Mafee MF. Progressive hemifacial atrophy (Parry-Romberg disease). J Pediatr Ophthalmol Strabismus 1987 Jan-Feb; 24(1):27-36.

13. Pinheiro TP, Silva CC, Silveira CS, Botelho PC, Pinheiro M, Pinheiro JJ. Progressive hemifacial atrophy - case report. Med Oral Patol Oral Cir Bucal 2006 Mar;11(2):E112-E114.

14. Baskan EB, Kaçar SD, Turan A, Saricaoglu H, Tunali S, Adim SB. Parry-Romberg syndrome associated with borreliosis: could photochemotherapy halt the progression of the disease? Photodermatol Photoimmunol Photomed 2006 Oct;22(5):259-261.

15. Paprocka J, Jamroz E, Adamek D, Marszal E, Mandera M. Difficulties in differentiation of Parry-Romberg syndrome, unilateral facial sclerodermia, and Rasmussen syndrome. Childs Nerv Syst 2006 Apr 1;22(4):409-415.

16. Tang XJ, Liu W, Yang B, Shi L, Yin L, Zhang ZY. Parry-Romberg syndrome with rare maxillofacial deformities: a report on two cases. J Craniomaxillofac Surg 2014 Sep 30;42(6): 780-783.

17. Cory RC, Clayman DA, Faillace WJ, McKee SW, Gama CH. Clinical and radiologic findings in progressive facial hemiatrophy (Parry-Romberg syndrome). Am J Neuroradiol 1997 Apr 1;18(4):751-757.
18. Blitstein MK, Vecchione MJ. Parry-Romberg syndrome. Appl Radiol 2011 Feb;40:34-36.

19. Ong K, Billson FA, Pathirana DS, Clifton-Bligh P. A case of progressive hemifacial atrophy with uveitis and retinal vasculitis. Aust N Z J Ophthalmol 1991 Nov 1;19(4):295-298.

20. Bergler-Czop B, Lis-Święty A, Brzezińska-Wcisło L. Scleroderma linearis: hemiatrophia faciei progressiva (ParryRomberg syndrome) without any changes in CNS and linear scleroderma "en coup de sabre" with CNS tumor. BMC Neurol 2009 Jul;9:39.

21. Pichiecchio A, Uggetti C, Eggito MG, Zappoli F. ParryRomberg syndrome with migraine and intracranial aneurysm. Neurology 2002 Aug;59(4):606-608.

22. Matute RG, Alonso RE. Parry-Romberg syndrome. Med Clin (Barc) 2012;139:323.

23. Jun JH, Kim HY, Jung HJ, Lee WJ, Lee SJ, Kim DW, Kim MB, Kim BS. Parry-Romberg syndrome with en coup de sabre. Ann Dermatol 2011 Aug;23(3):342-347.

24. Lazaridou E, Giannopoulou C, Apalla Z, Fotiadou C, Trigoni A, Ioannides D. Parry-Romberg syndrome. J Dermatol Case Rep 2010 Nov;4(2):30-32.

25. Grippaudo C, Deli R, Grippaudo FR, Di Cuia T, Paradisi M. Management of craniofacial development in the ParryRomberg syndrome: report of two patients. Cleft Palate Craniofac J 2004 Jan;41(1):95-104. 